\title{
Questionnaire Investigation on Jewelry/Accessory Internet Shopping and Its Analysis Utilizing Bayesian Network
}

\author{
Tsuyoshi Aburai ${ }^{1}$, Kazuhiro Takeyasu ${ }^{2}$ \& Chie Ishio $^{3}$ \\ ${ }^{1}$ Robotics \& Design Center, Osaka Institute of Technology, Japan \\ ${ }^{2}$ College of Business Administration, Tokoha University, Japan \\ ${ }^{3}$ Cherish CO., LTD, Japan \\ Correspondence: Tsuyoshi Aburai, Robotics \& Design Center, Osaka Institute of Technology, 5-16-1 Omiya, \\ Asahi-ku, Osaka, 535-8585 Japan. Tel: 81-6-6180-4083. E-mail: ABURAI.Tsuyoshi@josho.ac.jp
}

Received: October 25, 2015

Accepted: November 23, $2015 \quad$ Online Published: December 25, 2015

doi: 10.5539/ibr.v9n1p165

URL: http://dx.doi.org/10.5539/ibr.v9n1p165

\begin{abstract}
Recently, the numbers of jewelry/accessories buying via the Internet are increasing, especially for young people. They often have difficulty deciding what kinds of jewelry/accessories, because there are many kinds of jewelry/accessories to choose from. Consulting service to support decisions is required for these matters. In this paper, a questionnaire investigation is executed for the purchasing on-line network, used for jewelry/accessory purchasing in order to get instructions for an on-line network consulting service. Nearly 500 sample data are collected. In this research, we construct the model utilizing Bayesian Network and causal relationship is sequentially chained by the characteristic of customer, the purchase budget and the accessory type. We analyzed them by sensitivity analysis and $\log$ odds ratio was also calculated. Hypothesis testing result was compared with this one. The method to utilize log odds ratio in the sensitivity analysis under the Bayesian Network proved to be sensitive and useful. This method would be applicable in many Bayesian Network analyses. These are utilized for constructing a much more effective and useful on-line network consulting service.
\end{abstract}

Keywords: jewelry, questionnaire investigation, Bayesian Network, odds ratio

\section{Introduction}

Owing to the prevailing Internet, new businesses such as jewelry selling via Internet with on-line consultation, what kind of jewelry/accessory for gift purchasers would be better to choose, is becoming a big trend. Purchasers via Internet have various purchasing patterns and they may have significant relationship with their characteristics and the circumstances they are in. Therefore, if we can make clear the relationship between these, we would be able to make a much more effective marketing plan and execute efficient sales promotion for each of them.

For these purposes, we created a questionnaire investigation of jewelry/accessory purchasing. In recent years, Bayesian Network is highlighted because it has the following good characteristics (Neapolitan, 2004).

- Structural Equation Modeling requires normal distribution to the data in the analysis. Therefore it has a limitation in making analysis. But Bayesian Network does not require specific distribution type to the data. It can handle any distribution type.

- It can handle the data which include partial data.

- Expert's know-how can be reflected in building Bayesian Network model.

- Sensitivity analysis can be easily executed by settling evidence. We can estimate and predict the prospective purchaser by that analysis.

- It is a probability model having network structure. Related items are connected with directional link. Therefore understanding becomes easy by its visual chart.

In this research, it is suitable to utilize Bayesian Network to analyze jewelry / accessory purchasing because each variable does not necessarily have normal distribution. Reviewing past researches, there are some related researches as follows. Takahashi et al. (2008) made analysis for the future home energy utilizing Bayesian Network. Tsuji et al. (2008) made analysis concerning preference mining on future home energy consumption. 
There are some papers concerning purchase behavior in the shop (Tatsuoka et al., 2008a; Tatsuoka et al., 2008b). But we can hardly see the analysis concerning jewelry / accessory purchasing utilizing Bayesian Network.

In this paper, a questionnaire investigation is executed for on-line network jewelry/accessory purchasing in order to get instructions for an on-line network consulting service. These are analyzed by using Bayesian Network.

The analysis utilizing Bayesian Network enabled us to visualize the causal relationship among items. Furthermore, sensitivity analysis combined with odds ratio analysis brought us estimating and predicting the prospective purchaser. Hypothesis testing is executed before Bayesian Network analysis in order to confirm the effectiveness of this new approach.

These are compared and the method to utilize log odds ratio in the sensitivity analysis under the Bayesian Network proved to be sensitive and useful. This method would be applicable in many Bayesian Network analyses.

The rest of the paper is organized as follows. Outline of questionnaire research is stated in section 2. In section 3, Hypothesis testing is executed. In section 4, Bayesian Network analysis is executed which is followed by the sensitivity analysis in section 5. Section 6 is a summary.

\section{Outline of Questionnaire Research and Examinees}

\subsection{Outline of Questionnaire Research}

Outline of questionnaire research is as follows.

Scope of investigation: Young Persons, Japan

Period : May 2008-June 2009

Method: Mail and self writing

Collection: Number of distribution 1,500, Number of collection 421 (collection rate 28.1\%)

Analysis methods are as follows.

Questionnaire results are analyzed in three methods. First, analysis by Cross Tabulation is executed in 3 in order to confirm hypotheses. Second, analysis by Bayesian Network is executed in 4 in order to clarify and visualize the causal relationship among the items. Third, analysis by sensitivity analysis is executed in 5 in order to predict the prospective purchaser as is shown in Table 1.

Table 1. Analysis procedure

\begin{tabular}{ccc}
\hline Step & Aim of analysis & Used Method \\
\hline (1) & Confirm hypotheses & Cross Tabulation \\
(2) & Build Bayesian Network in order to clarify and visualize the & Bayesian Network Analysis \\
& causal relationship among items & Sensitivity Analysis \\
\hline
\end{tabular}

\subsection{Outline of Examinees}

(1) $\operatorname{Sex}(\mathrm{Q} 45)$

Male: $67 \%$, Female: $33 \%$

(2) Age (Q46)

Under 18: $1 \%, 18 \sim 22: 36 \%, 23 \sim 27: 15 \%, 28 \sim 32: 12 \%, 33 \sim 37: 14 \%, 38 \sim 42: 10 \%, 43 \sim 47: 4 \%$, More than 48: $8 \%$

(3) Occupation (Q47)

Student: 39\%, Officer: 2\%, Company Employee: 46\%, Clerk of Organization: 1\%, Independents: 6\%, Miscellaneous: 6\%

(4) Address (Q48)

Osaka: 57\%, Hyogo: 7\%, Kagawa: 6\%, Wakayama: 5\%, Fukui: 5\%, Nara: 4\%, Others: $16 \%$ 


\section{Hypothesis Testing}

\subsection{Fundamental Ideas for Hypotheses}

We set 15 Themes as follows. These are extracted from the experience of the professionals.

\begin{tabular}{cl}
\hline Theme 1 & Female would esteem coupon much better than male does. \\
\hline Theme 2 & Those who make stress upon material or quality have rather high budget amount. \\
Theme 3 & There is not so much utilization of Internet shopping for the people who like sports and shopping. \\
Theme 4 & Those who like indoor lifestyle use Internet frequently. \\
Theme 5 & Company employee uses Internet Shopping much more frequently than student or housewife. \\
Theme 6 & Those who like shopping esteem brand, trend and design. \\
Theme 7 & Budget amount is large when he / she has someone to consult with in making present. \\
Theme 8 & Those who like shopping do not hesitate to consult with sales clerk. \\
Theme 9 & Those who often use Internet shopping live far from urban. \\
Theme 10 & Those who like shopping also like Internet shopping. \\
& Presents from male to female consist of mainly Ring and Necklace, while Pierced Earring and \\
Theme 11 & Bracelet from female to female. \\
Theme 12 & Fewer becomes the presenting frequency, as age grows up. \\
Theme 13 & Anxiety about net shopping grows larger as ages become young. \\
Theme 14 & Frequent utilization of Internet does not have direct correlation with the usage of Internet shopping. \\
Theme 15 & Average purchasing amount of money for Internet shopping by mobile is gradually increasing. \\
\hline
\end{tabular}

\subsection{The Results of Statistical Hypothesis Testing}

The results of statistical hypothesis testing are as follows.

Theme 1. Female esteems coupon much better than male does.

Null hypothesis: Female esteems coupon as male does.

Table 2. Cross tabulation result 1

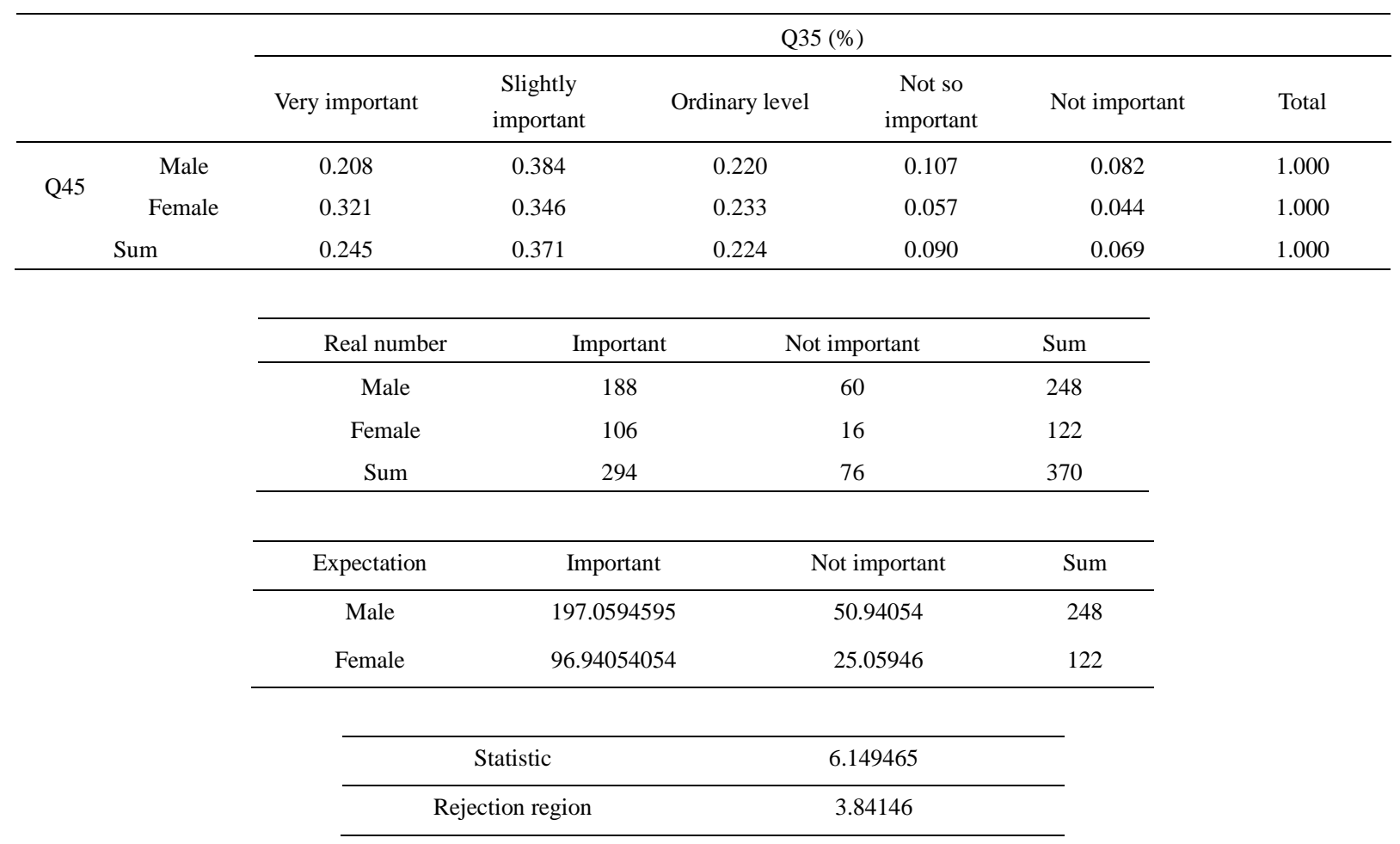


The hypothesis is rejected with 5\% significance level.

Therefore it can be said that "Female esteems coupon much better than male does".

Shop owner has an impression that many women respond to the promotion or campaign of coupon.

It is only women to inquire about campaign of coupon. Women seek the best timing to buy, while men often buy the goods when they need, whether the campaign is held or not.

Now, from the theme 2, we only show the results.

Theme 2. Those who do not make stress upon material or quality have rather low budget amount.

The hypothesis is not rejected.

Theme 3. There is not so much utilization of Internet shopping for the people who like sports and shopping.

The hypothesis is rejected with $9 \%$ significance level.

Theme 4. Those who like indoor lifestyle use Internet frequently.

The hypothesis is not rejected.

Theme 5. Company employee uses Internet Shopping much more frequently than student or housewife.

The hypothesis is rejected with $1 \%$ significance level.

Theme 6. Those who like shopping esteem brand, trend and design.

The hypothesis is rejected with $9 \%$ significance level.

Theme 7. Budget amount is large when he / she has someone to consult with in making present.

The hypothesis is not rejected.

Theme 8. Those who like shopping do not hesitate to consult with sales clerk.

The hypothesis is not rejected.

Theme 9. Those who often use Internet shopping live far from urban.

The hypothesis is rejected with $1 \%$ significance level.

Theme 10. Those who like shopping also like Internet shopping.

The hypothesis is rejected with $1 \%$ significance level.

Theme 11. Presents from male to female consist of mainly Ring and Necklace, while Pierced Earring and Bracelet from female to female.

The hypothesis is rejected with $1 \%$ significance level.

Theme 12. Fewer becomes the presenting frequency, as age grows up.

The hypothesis is rejected with $1 \%$ significance level.

Theme 13. Anxiety about net shopping grows larger as ages become young.

The hypothesis is rejected with $1 \%$ significance level.

Theme 14. Frequent utilization of Internet does not have direct correlation with the usage of Internet shopping.

The hypothesis is rejected with $1 \%$ significance level.

Theme 15. Average purchasing amount of money for Internet shopping by mobile is gradually increasing.

The hypothesis not rejected.

\subsection{Remarks}

From the Hypothesis testing, findings are as follows and following contents can be discussed.

/ Shop owner has an impression that many women respond to the promo-tion or campaign of coupon.

It is only women to inquire about campaign of coupon. Women seek the best timing to buy, while men often buy the goods when they need, whether the campaign is held or not.

/ It cannot be said that budget is not necessarily high even though consumers esteem material or quality. In particular, consumers cannot confirm the goods holding at their hands, therefore they confirm the explanation of material or quality at the site.

We often hear from many shop owners that they have experience of what consumers who buy only price 
deducted goods are severe in selecting goods. It can be said that those who are severe for price are also severe for quality.

/ It can be said that there are not so much utilization of Internet shopping for the people who like sports and shopping.

There who like sports and shopping would easily go out and search goods at real shop. It may be considered that they do not think highly of net shop.

/ There is not so much difference in the frequency of using Internet whether those who like indoor lifestyle or not.

Once, there was an image that indoor typed people often use Internet. But nowadays, it became common to use Internet whenever and wherever.

/ It can generally be said that company employee uses Internet shopping much more frequently than student or housewife.

Company employees are accustomed to use Internet and they have hard time to go out shopping while in week days.

Therefore they may use Internet for shopping. Actually, the most frequent access times to Cherish Co. Ltd. are around 21 o'clock. They may be making Internet shopping at home after work.

/ It can generally be said that those who like shopping esteem brand, trend and design. Those who like shopping are accustomed to go shopping and generally have information about brand, trend and design therefore thy have own standard what to buy.

/ Generally, there are few people to consult with sales clerk while shopping. It may be because they hear the request before making present. Sales talk of sales clerk may be backed away at any rate.

/ It is generally assumed that residents in urban area have less need to use Internet because shops are near.

But the actual order number is many for the residents in urban area. It does not depend upon the place where they live but lifestyle and/or hobby may have correlation for the utilization of Internet for shopping.

/ It can generally be said that those who like shopping also like Internet shopping. Internet shopping became popular and it is one of the style of shopping in general.

In particular, those who like shopping may feel convenient in selecting goods as there are so many goods sold in Internet shop.

/ It can generally be said that present from male to female consist of mainly Ring and Necklace, while Pierced earring and Bracelet from female to female.

Necklace is easiest to select when male makes present to female. It is because the strict size information is not required and the feeling of likes and dislikes are not so prominent.

As for Ring, pair ring is often selected by male. Female may buy ring for herself but it is rare to make present to her girlfriend. Pierced earring and Bracelet is not so high therefore it is easy to make present to her girlfriend.

/ It can generally be said that fewer becomes the presenting frequency, as age grows up.

When young (student or 20th), they have a chance to make present on Xmas or birthday. After married and having children, they make present to lover as well as children. When their children grow up, they often lose such a chance.

/ It can generally be said that anxiety about net shopping grows larger as ages become young. Meanwhile, some of the senior found to have less anxiety about net shopping. If they have experience of net shopping, they would feel less anxiety about it. 30th through 40th are under the ages that internet shopping has grown big. Once they have experience of purchasing via Internet and also feel that it is convenient and safe, then the market will grow larger.

/ It can generally be said that frequent utilization of Internet does not have direct correlation with the usage of Internet shopping. The big difference between them is whether it makes payment or not. Usually, Internet is frequently used for inquiry. But it cannot be said that they often make net shopping.

/ When the early stage for purchasing goods via cellular phone, customers generally bought rather cheap products than the case via PC. But nowadays, they became similar in purchasing amount. From now on, purchasing via smart phone would prevail. 


\section{Bayesian Network Analysis}

In constructing Bayesian Network, it is required to set an outline of the model reflecting the causal relationship among groups of items. Concept chart in this case is exhibited in Figure 1.

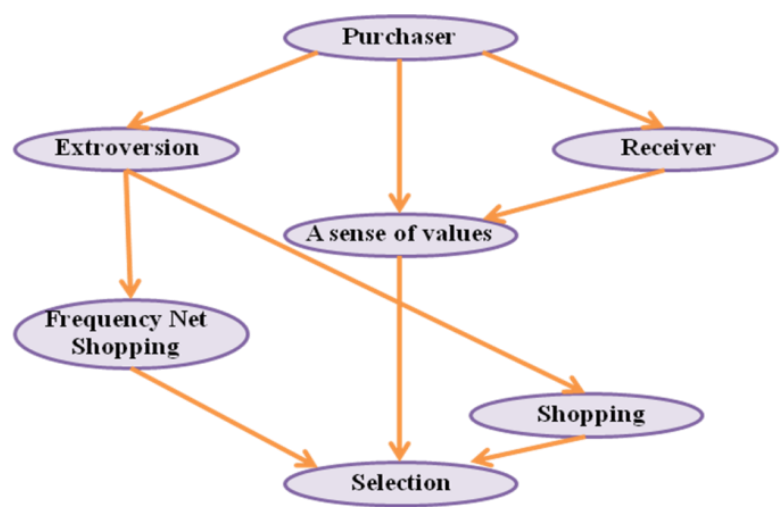

Figure 1. Node and Parameter

Based on this, model is built as is shown in Figure 2.

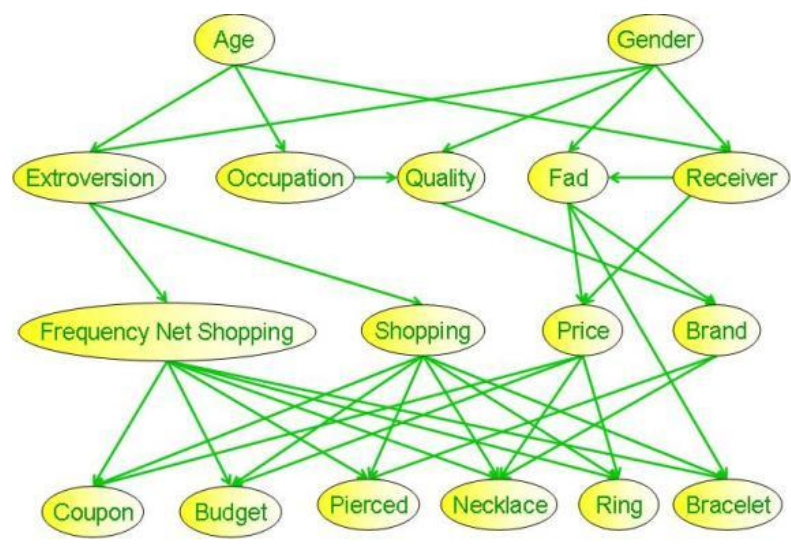

Figure 2. The relationship model

We used BAYONET software (http://www.msi.co.jp/BAYONET/). When plural nodes exist in the same group, it occurs that causal relationship is hard to set a priori. In that case, BAYONET system set the sequence automatically utilizing AIC standard. Node and parameter of Figure 2 are exhibited in Table 2.

Table 3. Node and parameter

\begin{tabular}{|c|c|c|c|c|c|c|}
\hline \multirow{2}{*}{ Group Name } & \multirow{2}{*}{ Node in Group } & \multicolumn{5}{|c|}{ Parameter } \\
\hline & & 1 & 2 & 3 & 4 & 5 \\
\hline \multirow{3}{*}{ Purchaser } & Age & Under22 & $23 \sim 32$ & $33 \sim 42$ & Over43 & \\
\hline & Gender & Male & Female & & & \\
\hline & Occupation & Students & Employee & Independent & Others & \\
\hline Receiver & Receiver & Lover & Parents & Sweet Heart & Myself & Others \\
\hline Extroversion & Extroversion & Outdoor & Indoor & Not Either & & \\
\hline $\begin{array}{l}\text { A sense of } \\
\text { values }\end{array}$ & $\begin{array}{c}\text { Fad, Brand, Praice, } \\
\text { Quality }\end{array}$ & Important & Ordinary & Not Either & & \\
\hline $\begin{array}{l}\text { Internet } \\
\text { Shopping }\end{array}$ & $\begin{array}{c}\text { Frequency_Net } \\
\text { Shopping }\end{array}$ & Often & Sometimes & Rarely & Never & \\
\hline Shopping & Shopping & Important & Ordinary & Not Either & & \\
\hline
\end{tabular}




\begin{tabular}{|c|c|c|c|c|c|}
\hline \multirow{3}{*}{ Selection } & Budget & $\sim 10000$ & $\sim 20000$ & $\sim 30000$ & Over 30000 \\
\hline & $\begin{array}{c}\text { Ring, Necklace, Pierced, } \\
\text { Bracelet }\end{array}$ & Buy & Not & & \\
\hline & Coupon & Important & Ordinary & Not & \\
\hline
\end{tabular}

Note. "Very important" and "Slightly important" are condensed into one as "Important" in order to decrease node number.

\section{Sensitivity Analysis}

Now, let's confirm whether the results of Cross Tabulation and the results of probabilistic inference by Bayesian Network coincide or not. We take up Hypothesis 1 as a case. Posterior probability is calculated by setting evidence as, for example, 1.0. Comparing Prior probability and Posterior probability, we can seek the change and confirm whether the Hypothesis is appropriate or not. In Hypotheses 1, set evidence as 1.0 for the "Male" in the group of "Gender", and also set evidence as 1.0 for the "Important" in the group of "Coupon". Generally, we can obtain more clear result when we set evidence to the contraposition item. We assume that "Female would esteem coupon much better than male does", therefore setting evidence 1.0 to "Male" would be suitable in this case. Table 3, 4 show the results of this attempt.

Table 4. Sensitivity analysis and odds ratio for "Male"

\begin{tabular}{|c|c|c|c|c|c|c|c|}
\hline \multirow{3}{*}{ Node } & \multirow{3}{*}{ Parameter } & \multicolumn{2}{|c|}{ Prior Probability } & \multicolumn{4}{|c|}{ Posterior Probability } \\
\hline & & & & & Male & & ODDS \\
\hline & & & $\begin{array}{l}\text { Common } \\
\text { logarithm }\end{array}$ & Male & $\begin{array}{l}\text { Common } \\
\text { logarithm }\end{array}$ & ODDS & $\begin{array}{l}\text { Common } \\
\text { logarithm }\end{array}$ \\
\hline \multirow{2}{*}{ Gender } & Male & 0.681 & 0.833 & 1.0 & - & - & - \\
\hline & Female & 0.319 & 0.503 & 0 & - & - & - \\
\hline \multirow{2}{*}{ Receiver } & Lover & 0.547 & 0.738 & 0.624 & 0.795 & 1.3744 & 1.3768 \\
\hline & Myself & 0.076 & 0.088 & 0.038 & 0.057 & 0.4802 & 0.6264 \\
\hline \multirow{2}{*}{ Extroversion } & Outdoor & 0.34 & 0.531 & 0.371 & 0.569 & 1.1450 & 1.1660 \\
\hline & Indoor & 0.325 & 0.511 & 0.284 & 0.453 & 0.8238 & 0.7925 \\
\hline Frequency_Net & Sometimes & 0.284 & 0.453 & 0.284 & 0.453 & 1.0000 & 1.0000 \\
\hline Shopping & Never & 0.257 & 0.409 & 0.257 & 0.409 & 1.0000 & 1.0000 \\
\hline Shopping & Important & 0.395 & 0.596 & 0.395 & 0.596 & 1.0000 & 1.0000 \\
\hline \multirow{2}{*}{$\mathrm{Fad}$} & Important & 0.756 & 0.878 & 0.745 & 0.872 & 0.9429 & 0.9466 \\
\hline & Not & 0.098 & 0.099 & 0.099 & 0.099 & 1.0113 & 1.0000 \\
\hline \multirow{2}{*}{ Price } & Important & 0.377 & 0.576 & 0.377 & 0.576 & 1.0000 & 1.0000 \\
\hline & Not & 0.28 & 0.447 & 0.287 & 0.457 & 1.0351 & 1.0412 \\
\hline Quality & Important & 0.683 & 0.834 & 0.662 & 0.82 & 0.9090 & 0.9067 \\
\hline \multirow{2}{*}{ Budget } & 20000 Over & 0.319 & 0.503 & 0.319 & 0.503 & 1.0000 & 1.0000 \\
\hline & 30000 & 0.149 & 0.173 & 0.15 & 0.176 & 1.0079 & 1.0210 \\
\hline Ring & Buy & 0.507 & 0.705 & 0.508 & 0.705 & 1.0040 & 1.0000 \\
\hline Necklace & Buy & 0.553 & 0.742 & 0.553 & 0.742 & 1.0000 & 1.0000 \\
\hline Pierced & Buy & 0.323 & 0.509 & 0.323 & 0.509 & 1.0000 & 1.0000 \\
\hline Bracelet & Buy & 0.228 & 0.357 & 0.229 & 0.359 & 1.0057 & 1.0087 \\
\hline \multirow{2}{*}{ Coupon } & Important & 0.526 & 0.721 & 0.525 & 0.72 & 0.9960 & 0.9950 \\
\hline & Not & 0.215 & 0.332 & 0.215 & 0.332 & 1.0000 & 1.0000 \\
\hline
\end{tabular}


Table 5. Sensitivity analysis and odds ratio for "Important"

\begin{tabular}{|c|c|c|c|c|c|c|c|}
\hline \multirow[b]{2}{*}{ Node } & \multirow[b]{2}{*}{ Parameter } & \multicolumn{2}{|c|}{ Prior Probability } & \multicolumn{4}{|c|}{ Posterior Probability } \\
\hline & & & $\begin{array}{l}\text { Common } \\
\text { logarithm }\end{array}$ & Important & $\begin{array}{l}\text { Important } \\
\text { Common } \\
\text { logarithm }\end{array}$ & ODDS & $\begin{array}{c}\text { ODDS } \\
\text { Common } \\
\text { logarithm }\end{array}$ \\
\hline \multirow{2}{*}{ Gender } & Male & 0.681 & 0.833 & 0.68 & 0.832 & 0.9954 & 0.9929 \\
\hline & Female & 0.319 & 0.503 & 0.32 & 0.505 & 1.0046 & 1.0080 \\
\hline \multirow{2}{*}{ Receiver } & Lover & 0.547 & 0.738 & 0.542 & 0.734 & 0.9800 & 0.9796 \\
\hline & Myself & 0.076 & 0.088 & 0.06 & 0.077 & 0.7760 & 0.8646 \\
\hline \multirow{2}{*}{ Extroversion } & Outdoor & 0.34 & 0.531 & 0.342 & 0.534 & 1.0089 & 1.0121 \\
\hline & Indoor & 0.325 & 0.511 & 0.324 & 0.51 & 0.9954 & 0.9960 \\
\hline Frequency_Net & Sometimes & 0.284 & 0.453 & 0.335 & 0.525 & 1.2700 & 1.3346 \\
\hline Shopping & Never & 0.257 & 0.409 & 0.245 & 0.389 & 0.9382 & 0.9200 \\
\hline Shopping & Important & 0.395 & 0.596 & 0.446 & 0.649 & 1.2331 & 1.2534 \\
\hline \multirow{2}{*}{ Fad } & Important & 0.756 & 0.878 & 0.758 & 0.879 & 1.0109 & 1.0094 \\
\hline & Not & 0.098 & 0.099 & 0.094 & 0.097 & 0.9549 & 0.9776 \\
\hline \multirow{2}{*}{ Price } & Important & 0.377 & 0.576 & 0.418 & 0.621 & 1.1869 & 1.2061 \\
\hline & Not & 0.28 & 0.447 & 0.224 & 0.35 & 0.7423 & 0.6662 \\
\hline Quality & Important & 0.683 & 0.834 & 0.683 & 0.834 & 1.0000 & 1.0000 \\
\hline \multirow[t]{2}{*}{ Budget } & $\begin{array}{c}\sim 20000 \text { Over } \\
30000\end{array}$ & 0.319 & 0.503 & 0.33 & 0.518 & 1.0515 & 1.0619 \\
\hline & & 0.149 & 0.173 & 0.134 & 0.127 & 0.8838 & 0.6954 \\
\hline Ring & Buy & 0.507 & 0.705 & 0.501 & 0.699 & 0.9763 & 0.9717 \\
\hline Necklace & Buy & 0.553 & 0.742 & 0.555 & 0.744 & 1.0081 & 1.0105 \\
\hline Pierced & Buy & 0.323 & 0.509 & 0.314 & 0.496 & 0.9594 & 0.9493 \\
\hline Bracelet & Buy & 0.228 & 0.357 & 0.225 & 0.352 & 0.9830 & 0.9784 \\
\hline \multirow{2}{*}{ Coupon } & Important & 0.526 & 0.721 & 1.0 & - & - & - \\
\hline & Not & 0.215 & 0.332 & 0 & - & - & - \\
\hline
\end{tabular}

We examined two cases as stated above. One is setting evidence 1.0 to "Male" and another one is to "Important" for coupon. Odds ratio is also calculated. If the Posterior Probability exceeds Prior Probability, its value exceeds 1.0 and if they are equal, the value becomes 1.0. Therefore odds ratio value makes a kind of a normalized index.

It is clear that female esteems coupon better than male by the result of Hypothesis testing (Hypothesis 1). We can see that female esteems coupon on the change of the probability, though the change is little.

It is often seen that the change of the probability becomes small when the hierarchical data cluster is distant. To this point, reinforcement learning, for example, may be one of an improving method to cope with this. For another improving method is to make shallow the depth of the hierarchy of the model. For another attempt of setting evidence 1.0 to "Male", we can observe that male does not esteem coupon. The value of Posterior Probability slightly decreased. This can also be made much more clear by introducing such as reinforcement learning method. Looking over other parameters, we can find that those who esteem coupon think it important about "Price " and we can also find that those who like shopping, and/or Internet shopping esteem coupon. We can derive the findings from these results that we would be better to focus upon "Female with small budget" while issuing coupon. In this way, we can utilize sensitivity analysis to focus target consumers in marketing.

\section{Conclusion}

Jewelry/accessory buying via the Internet is increasing, especially for young people. They often had difficulty deciding what kind of jewelry/accessory, because there were many kinds of jewelry/accessories to choose from. Consulting service to support decision was required for these matters. In this paper, a questionnaire investigation 
was executed for on-line network jewelry/accessory purchasing in order to get instruction for an on-line network consulting service. These were analyzed by using Bayesian network. We analyzed them by sensitivity analysis and $\log$ odds ratio was also calculated. Hypothesis testing result was compared with this one. The method to utilize log odds ratio in the sensitivity analysis under the Bayesian Network proved to be sensitive and useful. This method would be applicable in many Bayesian Network analyses. These would be utilized for constructing a much more effective and useful on-line network consulting service. Examining such trials should be traced hereafter.

\section{References}

Neaplitan, R. E. (2008). Learning Bayesian Networks. Artificial Intelligence, Prentice Hall.

Takahashi. A., Aoki, S., Tsuji, H., \& Inoue, S. (2008). Bayesian Network for Future Home Energy Consumption. 31st edition of the Annual German Conference on Artificial Intelligence (KI2008), To Appear in Lecture Notes on Computer Science, Springer. http://dx.doi.org/10.1007/978-3-540-85845-4_46

Tsuji. H., Kojima, M., Takahashi, A., Nakano, M., Aoki, S., Inoue, S., Asari, K., \& Mimura, E. (2008). Preference Mining on Future Home Energy Consumption (pp. 3697-3701). IEEE International Conference on Systems, Man \& Cybernetics (IEEE/SMC 2008). http://dx.doi.org/10.1109/icsmc.2008.4811874

Tatsuoka, K., Tetsu, Y., \& Junzo, M. (2008). Analysis on Purchase Behavior According to Display Way of merchandise by Bayesian Network. J. Archit. Plann., 73(633), 2349-2354. http://dx.doi.org/10.3130/aija.73.2349

Tatsuoka, K., Tetsu, Y., \& Junzo, M. (2008). Analysis on Relationship Between Layout of Display Cases ad Purchase Behavior by Bayesian Network. J. Archit. Plann., 73(634), 2633-2638.

\section{Appendix}

Questionnaire Concerning the Purchasing of Jewelry/Accessories for Gifts Please answer the following questions. Please write down $\circ$ to the answering items. Plural selection is allowed for Question 1, 13, 14, 17, 20, $39,40,43$, 44. Select (1)-(5) of the right column for the Question 2-11, 21-29, 32-36.

1. When you make a gift of jewelry/ accessory to someone, what point do you stress? (Plural Answers Allowed)

Q1 (1) Price (2) Brand (3) Trend/Design (4) Raw Materials/Quality (5) Kind/Items (6) Response of the shop members

(7) Existence of Certification (8) Relatively Cheap (9) Desire of the receiver of the gift (10) Miscellaneous ( )

2. When you choose, how is the importance of each item?

\begin{tabular}{|c|c|c|c|c|c|}
\hline Importance & 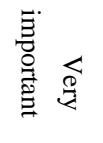 & 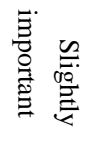 & 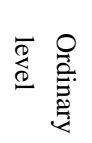 & 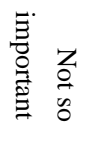 & 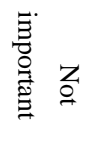 \\
\hline Q2 Price & (1) & (2) & (3) & (4) & (5) \\
\hline Q3 Brand & (1) & (2) & (3) & (4) & (5) \\
\hline Q4 Trend/Design & (1) & (2) & (3) & (4) & (5) \\
\hline Q5 Raw Materials/Quality & (1) & (2) & (3) & (4) & (5) \\
\hline Q6 Kind/Items & (1) & (2) & (3) & (4) & (5) \\
\hline Q7 Response of the shop members & (1) & (2) & (3) & (4) & (5) \\
\hline Q8 Existence of Certification & (1) & (2) & (3) & (4) & (5) \\
\hline Q9 Relatively Cheap & (1) & (2) & (3) & (4) & (5) \\
\hline Q10 Desire of the receiver of gift & (1) & (2) & (3) & (4) & (5) \\
\hline Q11 Miscellaneous ( ） & (1) & (2) & (3) & (4) & (5) \\
\hline
\end{tabular}

3. How much do you spend for one gift? [Unit: yen]

$\mathrm{Q} 12$ (1) $\sim 5,000$ (2) $\sim 10,000$ (3) $\sim 15,000$ (4) $\sim 20,000$ (5) $\sim 25,000$ (6) $\sim 30,000$ (7) more than that 
4. What kind of jewelry/accessory have you given? (Plural Answers Allowed)

Q13 (1) Ring (2) Necklace/ Pendant (3) Pierced earrings (4) Bracelet/Bungle (5) Brooch (6) Necktie Pin (7) Miscellaneous ( )

5. Why did you select them? (Plural Answers Allowed)

Q14 (1) Desire of the receiver (2) Trend (3) Because it was popular (4) Famous entertainers have them (5) Recommendation of the sales person in the shop (6) Budget (7) Special Sales (8) Miscellaneous ( )

6. Who do you consult with when you choose?

Q15 (1) Lover (2) Friend (3) Sales person of the shop (4) Do not consult with anybody (5) Miscellaneous ( )

7. Where do you buy gifts?

Q16 (1) Department Store (2) Jewelry/Accessory Shop (3) Remote Sales by Catalogue (4) Internet Shop (5) Miscellaneous ( )

8. Why is it? (Plural Answers Allowed)

Q17 (1) Desire of the receiver (2) Reliability of the shop (3) Plenty of items (4) There are favorite brands (5) Specified shop to buy(Always buy from the shop) (6) Friends often shop there (7) Rather cheap compared with quality (8) Able to get additional points when using a credit card (9) There is DM(Direct Mail) guidance when gift seasons come (10) Miscellaneous ( )

9. Whom do you make a gift to?

Q18 (1) Lover (2) Father/Mother (3) Children (4) Sweet heart (5) Myself (6) Miscellaneous ( )

10. How many times do you make gifts in a year?

Q19 (1) Once (2) Twice (3) Three times (4) Four times (5) More than that (6) None (Reason: )

11. On what occasions do you give presents? (Plural Answers Allowed)

Q20 (1)Birthday (2) Xmas (3) Valentine day (4) White day (5) Grown up anniversary (6) Wedding Anniversary (7)
Congratulate for birth (8) Congratulate for getting job (9) Congratulate for commencement of studying at school (10)
Miscellaneous ( )

12. What is your hobby?

\begin{tabular}{|c|c|c|c|c|c|}
\hline Importance & 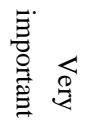 & 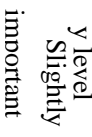 & 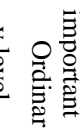 & 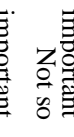 & $\underset{.}{z}$ \\
\hline Q21 12-1 Sports: (1) Baseball (2) Football (3) Tennis (4) Miscellaneous ( ) & (1) & (2) & (3) & (4) & (5) \\
\hline $\begin{array}{l}\text { Q22 12-2 Reading Books: (1) Novel (2) Business Affair (3) Weekly Magazine (4) Comic } \\
\text { (5) Miscellaneous ( ) }\end{array}$ & (1) & (2) & (3) & (4) & (5) \\
\hline Q23 12-3 Shopping & (1) & (2) & (3) & (4) & (5) \\
\hline Q24 12-4 Traveling: (1) Sightseeing (2) Hot Springs (3) Gourmet (4) Miscellaneous ( & (1) & (2) & (3) & (4) & (5) \\
\hline Q25 12-5 Music: (1) Classic (2) Western POPS (3) Japanese POP (4) Miscellaneous ( & (1) & (2) & (3) & (4) & (5) \\
\hline Q26 12-6 Movie: (1) Love (2) Action (3) Comedy (4) Miscellaneous () & (1) & (2) & (3) & (4) & (5) \\
\hline Q27 12-7 Theater: (1) Song (2) Dance/Ballet (3) Drama (4) Miscellaneous ( ) & (1) & (2) & (3) & (4) & (5) \\
\hline $\begin{array}{l}\text { Q28 12-8 Drinking: (1) Beer (2) Wine (3) Japanese wine-sake (4) Japanese liquor-shochu } \\
\text { (5) Miscellaneous ( ) }\end{array}$ & (1) & (2) & (3) & (4) & (5) \\
\hline Q29 12-9 Miscellaneous: ( ） & (1) & (2) & (3) & (4) & (5) \\
\hline
\end{tabular}


13. What kind of lifestyle do you like?

Q30 13-1 Pleasure: (1) Outdoor (2) Indoor (3) Not either

Q31 13-2 Work: (1) Desk Work (2) Outdoor activity such as visiting sales (3) Not either

14. Which method of payment do you want to choose?

\begin{tabular}{|c|c|c|c|c|c|}
\hline Importance & 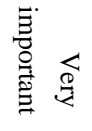 & 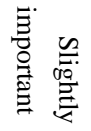 & 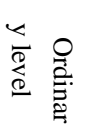 & 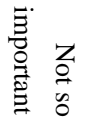 & 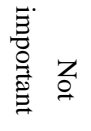 \\
\hline Q32 14-1 (1)Cash/Cash on Delivery & (1) & (2) & (3) & (4) & (5) \\
\hline Q33 14-2 Credit Card & (1) & (2) & (3) & (4) & (5) \\
\hline Q34 14-3 Discount & (1) & (2) & (3) & (4) & (5) \\
\hline Q35 14-4 Point Card/Coupon & (1) & (2) & (3) & (4) & (5) \\
\hline Q36 14-5 Miscellaneous ( ） & (1) & (2) & (3) & (4) & (5) \\
\hline
\end{tabular}

15. How often do you use the Internet?

Q37 (1) Very often (2) Sometimes (3) Rarely (4) Never

16. How do you use Internet?

Q38 16-1 How often do you use Internet Shopping?: (1) Very often (2) Sometimes (3) Rarely (4) Never

Q39 16-2 If you have answered "Yes"(16-1(1)(2), tell us the reason why. (Plural Answers Allowed)

(1) Convenient (2) Able to compare goods easily (3) Cheap (4) Plenty of goods (5) Able to consult with other people (6) Miscellaneous ( )

Q40 16-3 If you have answered "No"(16-1(3)(4), tell us the reason why. (Plural Answers Allowed)

(1) Difficult to buy (2) anxious (3) Can not observe actual goods (4) Can not identify which shop is good (5)

Can not get goods immediately (6) Miscellaneous ( )

Q41 16-4 If you have answered "Yes", which method do you use? (1) PC (2) Mobile Phone (3) Miscellaneous ( )

Q42 16-5 Do you want to buy jewelry/Accessory via the Internet? (1) Yes (2) Perhaps (3) No (4) I do not know

Q43 16-6 If you have answered "Yes"(16-5(1)(2), tell us the reason why. (Plural Answers Allowed)

(1) Convenient (2) Able to compare goods easily (3) Cheap (4) Plenty of goods (5) Able to consult with other people (6) Miscellaneous ( )

Q44 16-7 If you have answered "No"(16-5(3)(4)), tell us the reason why. (Plural Answers Allowed)

(1) Difficult to buy (2) anxious (3) Can not observe actual goods (4) Can not identify which shop is good (5) Can not get goods immediately (6) Miscellaneous ( )

17. Ask about yourself?

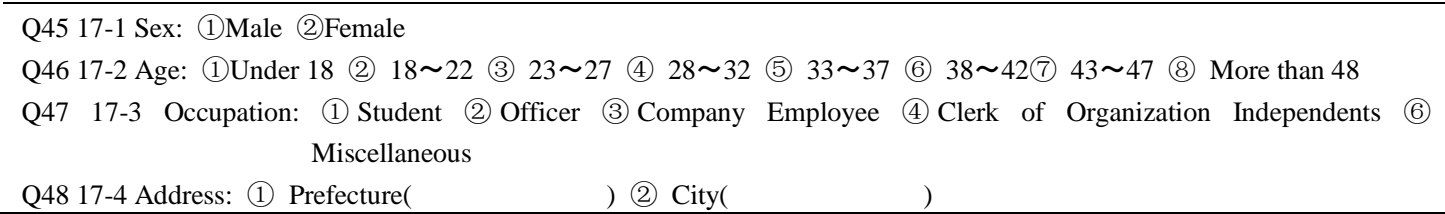

\section{Copyrights}

Copyright for this article is retained by the author(s), with first publication rights granted to the journal.

This is an open-access article distributed under the terms and conditions of the Creative Commons Attribution license (http://creativecommons.org/licenses/by/3.0/). 